\title{
28 Research Soure Ethical practice in medicine: a review
}

\author{
Kasaw Adane ( $\nabla$ kswadane@gmail.com ) \\ University of Gondar https://orcid.org/0000-0002-7781-5692 \\ Ligabaw Worku \\ University of Gondar \\ Teshiwal Deress \\ University of Gondar \\ Adino Tesfahun \\ University of Gondar
}

\section{Research article}

Keywords: medical ethics, ethical practice, quality service

Posted Date: January 29th, 2020

DOI: https://doi.org/10.21203/rs.2.22243/v1

License: (1) (1) This work is licensed under a Creative Commons Attribution 4.0 International License.

Read Full License 


\section{Abstract}

Objective

A patient with health problems seek healthcare services from healthcare professionals. Their patientprovider relationships are usually affected by roles, gifts, services, and physical contact. The major ethical healthcare practices focus on respecting patient's freedom and basic human rights. However, there are only limited references materials issued on medical ethics and ethical medical practices. Hence, this review article tries to describe the important aspects of ethical practices in healthcare delivery.

\section{Methods}

Initially, idea conceptualization, planning and keyword defining were for the development of this material. The keywords were medical ethics, code of ethics, bioethics, ethical practice, quality service and healthcare ethics.

Result

Then, two authors independently assessed published materials using EndNote ${ }^{\circledR}$ program from PubMed (NML) and Google Scholar databases. Finally, from a total of 721 full-text articles downloaded, 34 published article meeting inclusion criteria were included in this article.

Conclusion

Adherence to high ethical and moral standards, responding to societal needs and reflection social contract, subordinating self-interest to the interest of others and the manifestation of the core human values are all expected from healthcare professionals. Ethical and legal dimensions of medicine are very important. Hence, providing high-quality patient care at low cost and compliance with ethical and moral standards is the most common reason for the incompliance with medical ethics. Hence, healthcare professionals are expected to have a minimum level of knowledge on ethical concepts, favorable attitude, and a minimum level of skill to comply with regulatory and ethical requirements in all situations.

\section{Background}

The earliest and most meticulous book was written by Al-Ruhawi and Al-Razi over thousands of years ago [1]. Nowadays, medical ethics is a vital element of medicine for clinical, medical and beneficial public health services with the lowest risks [2]. Medical students commonly oath at graduation ceremony promising to be competent and act to the best interest of the sick [3].

The three layers of an "Onion Model" of three layers signifying the essential elements of moral value. The outer layer represents the knowledge and adherence to the principles and duties; the middle layer the gradual value internalization through deliberate practice, and the center layer core value represents the 
ultimate development of virtuous character by which practices are habituated and defaulted even at the time of high stress [4].

Scientific and contextual curriculums designed with associated technical skills [2] enable graduates to understand and exercise high personal values by applying theories and models during planning, execution and evaluation phases of healthcare rendering processes [5]. An integrated system of actions, rules and moral principles of ethics [6] is primarily concerned with healthcare for the gain of the patients [3]. The legal and ethical aspects of medicine are essential elements of clinical practices [1]. Doctors, researchers, ethical review boards, legislators, and policymaker are stakeholders interested in ethical compliance [7]. Patient and healthcare providers require contractual agreement and are free to enter into or decline it. The role of doctors is minimizing the pain of sufferings within the scope of their current level of knowledge and competence. Hence, medical ethics is highly important in healthcare practice [8].

The core principles of medical ethics orbits around fair and quality healthcare services [9]. The problems of ethics and ethical practices have deep roots emerge from culture, politics, and long developmental history of the healthcare services industry [10]. By its very nature, seeking healthcare services are naturally universal [3] and providing high-quality patient care is the responsibility of healthcare professionals [11].

The chief mission of medical ethics is to protect patient's vital interests in getting proper medical services with minimum errors if it is inevitable [7]. The expectation of patients is obtaining kind, humble, compassionate, honest, trustworthy, respectful and confidential [1] services consistent with their best interest [12].

Ethical services reflect the social needs, complies with subordinate self-interests to the interest of others, manifest core human values during the healthcare delivery process [13]. However; there are also misconceptions, malpractices, unintended errors, lack of understanding which are common evils interrelated to ethical patient care. Therefore, this review increases the importance of ethical medical practices as an important quality requirement in healthcare rendering processes.

\section{Method And Materials}

The qualitative research design was used in developing this review. The review process followed the Preferred Reporting Items for Systematic Reviews and Meta-Analyses (PRISMA) guidelines [14]. The guideline was used for checking the eligibility of published materials issued in the English language by peer-reviewed journals. Conceivable key term combinations were done using Boolean operators AND and/or OR. Published articles issued by reputable journals were accessed from PubMed and Google Scholar databases. However, the searching strategy is not applicable by unique combination of keywords. Searching was done by KA and TD separately.

Published journals were subsequently screened, selected and checked using the title, abstract and fulltext articles check for eligibility. Duplications were also checked after articles were searched by the two 
investigators. Citation and referencing were done using EndNote $X^{5}$ version citation manager software to manage the citation. Data extraction was done independently using a predefined data extraction checklist. Inconsistent data between the two data abstracters were resolved by discussion and reconciliation. Data were abstracted using (first author, year of publication, setting) and key findings ('medical ethics, code of ethics, bioethics, and healthcare ethics) and additional related findings were paraphrased (fig 1 ). Then, after abstraction, relevant studies were included using texts and graphical presentation.

\section{Result}

Published articles issued by reputable journals using English language from 2010 to 2017 were used for this review. These articles were checked for duplication using "Find Duplicate" EndNote $®$ application software features and duplications were removed. A total of 721 full-text articles were downloaded used during the process of article selection. Finally, 34 articles were included for the development of this review material as shown in the figure given below (figure 1).

\section{General expectations of medical ethics}

Scientific knowledge, technical skill, and integrity of healthcare practitioners permit them to deliver fair and confidential healthcare services [1]. Sharing their acquired knowledge and skills are the most essential elements of clinical practices $[2,6,15]$. In contrast to this intentional withholding of new knowledge, skills and techniques for one's own personal gain is professionally prohibited and contributes little quality improvement benefits [15].

\section{Factors challenging the ethical practice of medicine}

Most characters, codes, oaths profess the virtues of medicine and medical professional itself [4]. Rendering fair healthcare services is influenced by culture, politics, and lengthy developmental history of the healthcare industry and its principal focus is respecting basic human rights and freedom of patients [9]. The behavior of the healthcare personnel is greatly influenced by the attitudes, students level of understanding and professionals healthcare within the context of social, political, cultural structures of the community [13]. The main focus of bioethics and moral relations revolves around ensuring social justice and human rights.

The future practice of medicine is influenced by the socio-political, education and economic factors [10]. The rapidly changing environment demands ethical medical practices. The advancement of healthcare technology in healthcare still brings more challenges to the existing practice of medicine.

An accessible and affordable quality indicator variable is among the moral and economic aspects of the problems in healthcare rendering processes [3]. Practically, the health system itself is a model of 
inequality [16]. The sector is stated as social health inequality quoted "an elephant in the room" [11]. Healthcare under a wider range of circumstances usually leaves unresolved options which provide doctors the right to live under undefined situations [17].

Private for-profit industries are liable to corruption - business-driven conflicts of interests-in addition to the moral ruins of the individuals and/or groups in exchange for more revenue are becoming more common [16]. This is confounded by the absence of clear and comprehensive guideline and legal frame governing all the conceivable options at all time with the principle of "one size fits all'.

The mere newness or obsolesce of technology is not acceptance or rejection criteria but on its quality of meeting the best interest of the patient [10]. The right technology valuing moral sentiments and upscaling the quality of care must be selected and installed in the healthcare industry. Implementing new technologies demands new roles with new ethical responsibilities [18]. Technology influence [10] the complexity of modern care [19] such as the issue of abortion and stem cell research [7], and placebo [20] has been increasing the challenges to medical practices. However, failure to provide standard services must be corrected by the criminal justice system during serious violations of codes of practices healthcare professionals [21].

\section{The duty of the physician and the rights of the patient}

Physician-patient relationships rely on valuing essential moral ethics of medical care [10]. In preference, independent, unbiased, impartial, free from interest-driven conflicts and services directed towards the best interest of the patient is most appreciated [22]. Fair healthcare services increase patient's satisfaction [11]. Highly ethical and morally standardized services are the core concern of human values [13] for compliance with standardized services [4]. This is a fundamental focus of such physician-patient relationships as a core of medicine [23].

According to 'Bolam' doctors are free of guilty or negligence for practices accepted by responsible expert whereas according to 'Montgomery' doctors are expected to give the fullest possible information including all possible options including the rare ones [24]. However; it is better for the patients to have the right to obtain accurate information from the right source which improves patient satisfaction [1].

Physicians must secure consent before referring patients [25]. Informed consents are accepted only after communicating detail enough information [26]. Therefore, physicians must communicate benefits and/or potential risks of intervention or procedure before obtaining informed consent from the patient or their guardians in the case minors and mentally impaired patients [1].

\section{Determinants of good provider-patient relationships}

Patients unable to cope with current health situations are vulnerable and dependent to seek services from professionals [3]. They usually establish a voluntary contract and participate in decision-making [27]. 
Good contracts and relationships build, develop, and maintain confidence for the better treatment outcome and improved patient satisfaction $[2,11]$. The underlying patient's autonomy, style of communication, doctor's empathy, continuity and absence of conflict of interests are the basis for maintaining the established good relationships [27].

Doctors and clients usually face challenges while bargaining [11] and establishing contractual relationships which are ideally continuing or decline based on their free will [22]. The physician can only decline agreement if patient's health situation which is not within the reach of the current competence level and/or the patient does not respond to the treatment and/or procedure but not on race, color, religion, national origin, sexual orientation, gender, and any other variable [22].

\section{Patient's concern}

Patients are concerned about the quality aspects of healthcare services. The most common deceptions and breach of the patient's secrets are among the important patient concerns why wonder and worry about its trustworthiness [28]. These affects healthcare-seeking behavior of patients.

Providing affordable service for the patients in the interest of the patients. Over seventy percent of the healthcare industry is financed through out-of-pocket expenditure [16]. Such financing schemes favor the rich who can afford whereas the system often deprives the poor who is deserving and could not assess the services. The mechanism could not ensure the fundamental universal human right of accessing the basic healthcare services [7].

Collaborative works urged to compete in an ever-increasing and challenging complex modern medicine to deliver safe patient care [19]. Patients are more obsessed with decisions valuing their rights [29] and are concerned about their participation in decision-making [30]. Pessimistic healthcare providers usually use persuasive languages affecting their decisions without the full disclosure of detail enough information on diagnosis, physical examination, treatment risk, benefits, and side effects, qualification and professional achievement of treating physician, confidentiality, alternative opinion, the surgical procedure risks, the right to access medical record on request before asking patient's consent [31]. Healthcare services quality and the process should not be discriminatory and fair services should be provided equally irrespective of the patient's background [32].

\section{When to violate ethical principles in medical practices}

Patient private confidentiality information may be broken if the harm of maintaining overrides its benefits and the interests of the public when considered with the lesser evil on individual [1]. Advancements in medical knowledge bring multifaceted problems in the healthcare industry.

Clinical trial research applied on human population when new drugs or procedures for the intention of services quality improvement on the expense of known risks are acceptable and justifiable reasons to 
publish findings at scientific journals [33]. Protecting society and individual against some prejudice ensures the public interest and prevent public damage at the expense of lesser evil on the individual and/or the community.

\section{The scope of ethics in medicine}

The duties and responsibilities of physicians may go beyond the individual and reach the community [34]. The ethical codes of the Istanbul Protocol focus on common principles of legal grounds of healthcare ethics, the profession, and obligation of healthcare professionals [21].

The basic principles of standards and quality comply with professional codes ethics targeting towards the patient's rights, wellbeing, and faith with common obligations of healthcare provider during healthcare rendering processes [21].

On $10^{\text {th }}$ of August 2009, Erdogan was arrested politically. After ten days, transported to the hospital and died there shortly after his arrival. The hospital reported as if hunger strike associated pulmonary edema. His family members observed his corpse while washing his corpse and noticed many traces of physical abuse. Annoyed with the situation, several of his relatives distracted the police stations while others tore the burial shroud, took pictures and make films of the corpse.

Then, the Turkish Medical Association officially recognized the situation and rejected the hospital report and changed as electric shock and torture by hanging associated respiratory failure associated with multiple traumas. A jail sentence of five and half years was convicted by the culprit on the perpetrator because of violating medical ethics of negligence related homicide of the perpetrator and report was fulfilling the principles of the Minnesota protocol [21].

Therefore; compliance with medical ethics is very important during diagnosis, treatment and/or procedure and even during post-intervention phases.

Medical services are considered as a sacred duty and Allah rewarded profession in Islam physicians. The Messenger of Allah asked them, 'Who is the best doctor among you?' They asked: Is there a preference among physicians? O Messenger of Allah? He said, 'the one who sent down the disease also sent down the cure [1].

Depending on the competence of the physicians, the outcome of the procedure or intervention may increase suffering and or improve the health condition of the patient.

\section{Challenges of medical ethics and modern technology}

Nowadays, medical ethics are violated commonly. Modern commercialized models of care favor violation of medical ethics resulting ruins of de-professionalization [3]. Top-level managers usually sign contracts 
for prescribing some company drugs more preferentially than others for top range cars and other incentives and this is becoming a more common experience in pharmaceutical industries and patients are abused for unnecessary expenses related to unrelated investigations and procedures for the purpose of milking patients [16]. Such interest has driven physician's decisions to cause intentional concealing of drug-related harm and patients to fail to prevent drug adverse impacts [11].

Moreover, the introduction of a third element computer for exchanging, archiving and retrieving information in medicine significantly change the practice of medicine [35]. However, the use of internet technology could potentially minimize psychological comfort felt when providers are present at the service office. Hence, modern healthcare is strongly influenced by the moral practices of healthcare professionals. Corruptions are becoming quite common in healthcare practice and professionals are losing their integrity is very important instead of valuing the patient's best interest. Hence, lots of remedial actions have to be taken by concerned stakeholders so as to minimize the increasing rate of avoidable patient suffering related to medical malpractices.

\section{Ethics and law}

Medical interventions and/or procedures usually intermingle with ethics and laws. The right way to practice is not always applicable similarly to all situations as there is not as "one size fits all" in principle. The best way to proceed with situations of an ethical dilemma is to decide on the favorability of interventions is to consult one's country legal frames. This in itself gives an autonomous right to doctor's to lie during complex and undefined situations.

For instance, interventions such as abortion under optional applicable and legally acceptable grounds may not have legal ground during other situations [17]. However, this could wrongly be interpreted during actual interventions centering the interest of clients, law, and ethics. Similarly, patenting human embryonic stem cell research is scientifically denied because of its destructive effect on human embryos and violating public morality [7].

\section{Knowledge, attitude, and practices of healthcare professionals}

Healthcare professionals are responsible to share knowledge which is used to accomplishing tasks successfully, promoting and improving the quality medical services [6]. Intentional withholding valuable healthcare information for one's own personal gain is not ethical and it is condemned [15]. Applying the proper knowledge of the ethical and legal aspects of medicine is an essential element in clinical practices [2]. Moreover; having a favorable attitude towards ethical practice is greatly influenced by the sociopolitical and environmental factors [13]. 
Rendering fair healthcare services is the core of medical ethics [9]. It is important to balance the individual and public interests [1]. Therefore, healthcare practitioners are expected to comply with ethical codes during the entire healthcare delivery processes [21]. Patients are highly worried about more serious violations of telling truth and keeping secrets [28]. Effective communication of accurate healthcare information about the problems increases patient satisfaction on medical interventions [1]. Hence, applying theories and models of health education lets health researchers and educators have a deep and comprehensive understanding of compliance with ethical behavior [5].

However; the healthcare system is the model of inequalities [16] because common social inequalities are experienced in the systems [11]. Therefore, standardizing the processes and ensuring fair and good quality patient care is a mandatory requirement in the healthcare industry.

\section{Conclusion}

Compliance with ethical guidelines is the concern of stakeholders. Therefore; it is important to explore the about the ethical issues and the experience of clinical practices to share information for more improved patient healthcare outcome so as to respond to difficult situations.

\section{Abbreviations}

NLM-National Library of Medicine

\section{Declarations}

\section{Ethical approval and consent to participate}

N/A

\section{Consent to publication}

Authors approved their consent for publication

\section{Availability of data and material}

$\mathrm{N} / \mathrm{A}$

\section{Funding}

N/A

\section{Acknowledgment}

The authors of this review article would like to acknowledge copyright holder publishers, journals, and authors whose materials are used for the development of this review material. 


\section{Competing for interest}

Authors have no conflicts of interests

\section{Authors' contributions}

KA: idea conception, Designing the research; searching journals and preparing the manuscript, and proofreading and approving the manuscript; and TD: idea conception, Designing the research; searching journals and preparing a manuscript, and proofreading and approving the manuscript

\section{Author's contribution}

\section{Author Details}

1University of Gondar, College of Medicine and Health Sciences, School of Biomedical and Laboratory Sciences, Unit of Quality Assurance and Laboratory Management

\section{Availability of data and materials}

N/A

\section{References}

1.Chamsi-Pasha H, Albar MA: Doctor-patient relationship. Islamic perspective. Saudi medical journal $2016,37(2): 121-126$.

2.Stirrat GM, Johnston C, Gillon R, Boyd K: Medical ethics and law for doctors of tomorrow: the 1998 Consensus Statement updated. Journal of medical ethics 2010, 36(1):55-60.

3.Pellegrino ED: Medical ethics in an era of bioethics: resetting the medical profession's compass. Theoretical medicine and bioethics 2012, 33(1):21-24.

4.McCammon SD, Brody H: How virtue ethics informs medical professionalism. HEC forum: an interdisciplinary journal on hospitals' ethical and legal issues 2012, 24(4):257-272.

5.Ghaffarifar S, Ghofranipour F, Ahmadi F, Khoshbaten M: Barriers to Effective Doctor-Patient Relationship Based on PRECEDE PROCEED Model. Global journal of health science 2015, 7(6):24-32.

6.Wu T, Li Y, Zhen S, Deng S, Zhang L, Fan C, Jia W, Zhong Z, Du L, Liu X et al: Joint statement on promoting development of publication ethics among medical journals in China. Journal of evidencebased medicine 2011, 4(4):214-216.

7.Hansson MG, Chadwick R: Is medical ethics doing its job? Journal of internal medicine 2011, 269(4):366-369. 
8.Datema TA, Oskam L, van Beers SM, Klatser PR: Critical review of the Stepwise Laboratory Improvement Process Towards Accreditation (SLIPTA): suggestions for harmonization, implementation and improvement. Tropical medicine \& international health: TM \& IH2012, 17(3):361-367.

9.Frewer A: Human rights from the Nuremberg Doctors Trial to the Geneva Declaration. Persons and institutions in medical ethics and history. Medicine, health care, and philosophy 2010, 13(3):259-268.

10.Giordano J: Respice...prospice: philosophy, ethics and medical care- past, present, and future. Philosophy, ethics, and humanities in medicine: PEHM 2010, 5:17.

11.Furler JS, Palmer VJ: The ethics of everyday practice in primary medical care: responding to social health inequities. Philosophy, ethics, and humanities in medicine: PEHM 2010, 5:6.

12.Bending ZJ: Reconceptualising the doctor-patient relationship: recognising the role of trust in contemporary health care. Journal of bioethical inquiry 2015, 12(2):189-202.

13.Parikh SM: Global health ethics and professionalism education at medical schools. The virtual mentor: VM 2010, 12(3):197-201.

14.Moher D, Liberati A, Tetzlaff J, Altman DG, Group P.: Preferred reporting items for systematic reviews and meta-analyses: the PRISMA statement. PLoS Med 2009, 6(e1000097).

15.AMA Code of Medical Ethics ' Opinions on Patenting Procedures and Devices. The virtual mentor: VM $2010,12(2): 96$.

16.Berger D: Corruption ruins the doctor-patient relationship in India. BMJ 2014, 348:g3169.

17.Oyer DJ: Playing politics with the doctor-patient relationship. The New England journal of medicine 2012, 366(24):2326-2327.

18.Dekkers W, Gordijn B: Conceptual analysis and empirical research in medical philosophy and medical ethics. Medicine, health care, and philosophy 2010, 13(1):1-2.

19.Kondro W: Medical errors increasing because of complexity of care and breakdown in doctor-patient relationship, physician consultant says. CMAJ: Canadian Medical Association journal = journal de I'Association medicale canadienne 2010, 182(13):E645-646.

20.Miller FG, Colloca L: The placebo phenomenon and medical ethics: rethinking the relationship between informed consent and risk-benefit assessment. Theoretical medicine and bioethics 2011, 32(4):229-243.

21.Furtmayr H, Frewer A: Documentation of torture and the Istanbul Protocol: applied medical ethics. Medicine, health care, and philosophy 2010, 13(3):279-286.

22.The AMA Code of Medical Ethics' Opinions on Respect for Civil and Human Rights. The virtual mentor: VM 2010, 12(8):644. 
23.Heyne T: Medical ethics and retail clinics. The virtual mentor: VM 2011, 13(9):612-619.

24.Lee A: 'Bolam' to 'Montgomery' is result of evolutionary change of medical practice towards 'patientcentred care'. Postgraduate medical journal 2017, 93(1095):46-50.

25.Prokopetz JJ, Lehmann LS: Physicians as fundraisers: medical philanthropy and the doctor-patient relationship. PLoS medicine 2014, 11(2):e1001600.

26.Dranseika V, Piasecki J, Waligora M: Relevant Information and Informed Consent in Research: In Defense of the Subjective Standard of Disclosure. Science and engineering ethics 2017, 23(1):215-225.

27.Shrivastava SR, Shrivastava PS, Ramasamy J: Exploring the dimensions of doctor-patient relationship in clinical practice in hospital settings. International journal of health policy and management 2014, 2(4):159-160.

28.Frader J, Kodish E, Lantos JD: Ethics rounds. Symbolic resuscitation, medical futility, and parental rights. Pediatrics 2010, 126(4):769-772.

29.Unnikrishnan B, Trivedi D, Kanchan T, Rekha T, Mithra P, Kumar N, Kulkarni V, Holla R, Talish M: Patients' Awareness About Their Rights: A Study from Coastal South India. Science and engineering ethics 2017, 23(1):203-214.

30.Skowron KB, Angelos P: Surgical Informed Consent Revisited: Time to Revise the Routine? World journal of surgery 2017, 41(1):1-4.

31.Compagnone C, Schatman ME, Rauck RL, Van Zundert J, Kraus M, Primorac D, Williams F, Allegri M, Saccani Jordi G, Fanelli G: Past, Present, and Future of Informed Consent in Pain and Genomics Research: Challenges Facing Global Medical Community. Pain practice: the official journal of World Institute of Pain 2017, 17(1):8-15.

32.Witon M, Strapagiel D, Glenska-Olender J, Chroscicka A, Ferdyn K, Skokowski J, Kalinowski L, Pawlikowski J, Marciniak B, Pasterk M et al: Organization of BBMRI.pl: The Polish Biobanking Network. Biopreservation and biobanking 2017.

33.Sismondo S, Doucet M: Publication ethics and the ghost management of medical publication. Bioethics 2010, 24(6):273-283.

34.Weaver R, Wilson I: Australian medical students' perceptions of professionalism and ethics in medical television programs. BMC medical education 2011, 11:50.

35.Wright A: You, me, and the computer makes three: navigating the doctor-patient relationship in the age of electronic health records. Journal of general internal medicine 2015, 30(1):1-2.

\section{Figures}




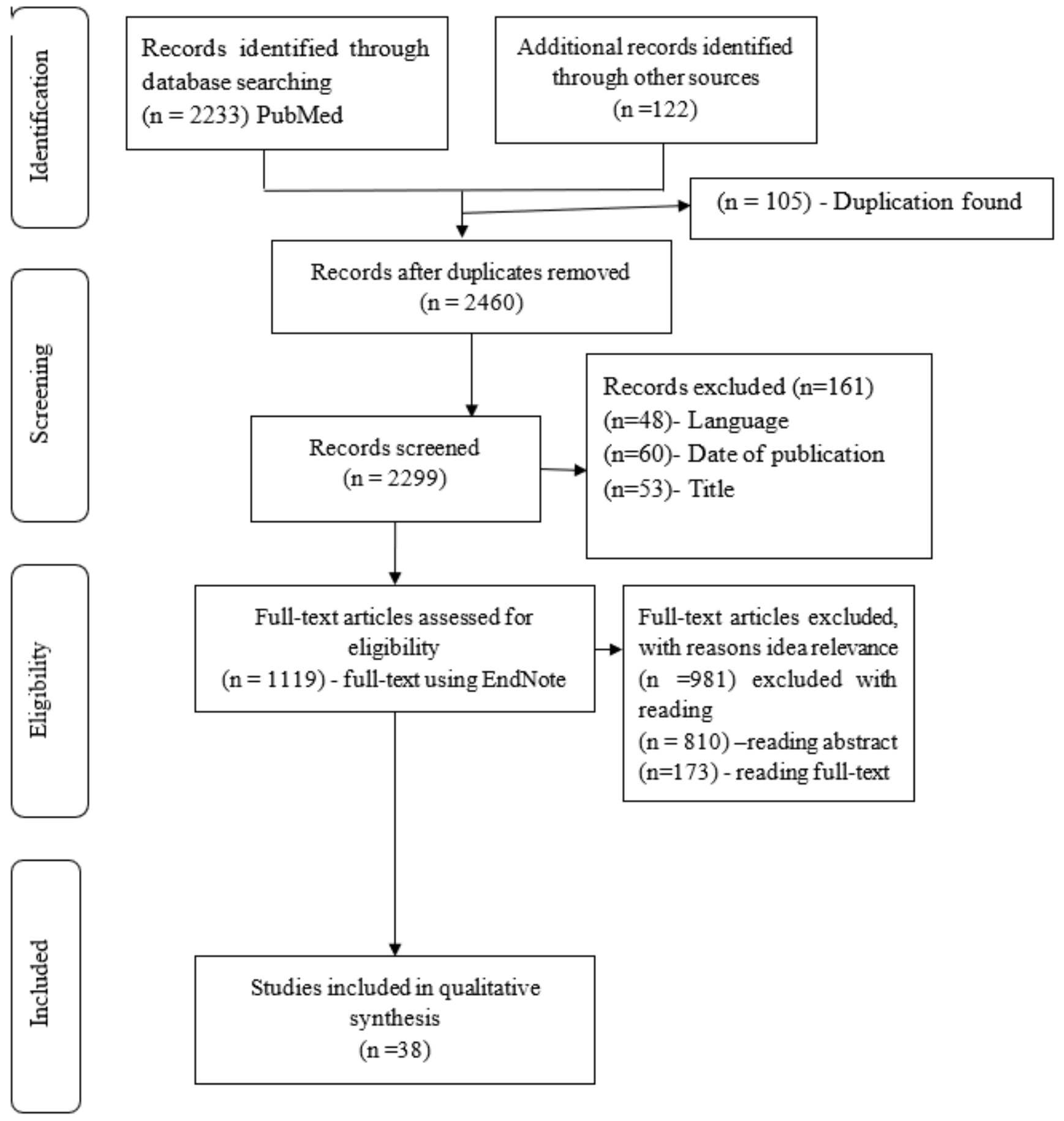

Figure 1

PRISMA flow diagram of article selection processes 